\title{
HIGH-TEMPERATURE RESEARCH
}

\author{
SYMPOSIUM AT THE UNIVERSITY OF CALIFORNIA, BERKELEY
}

\begin{abstract}
A SYMPOSIUM on "High Temperature : a Tool for the Future" was held on the campus of the University of California, Berkeley, California, during June 20-27. This meeting was sponsored by the Stanford Research Institute and the University of California. Most of the 600 attending the symposium were from the United States; but other countries were also represented.

The subjects were dealt with in three major categories, one each day, namely : methods for reaching high temperatures, materials for containing high temperatures, and processes occurring at high temperatures. The chairmen for the three-day meeting, successively, were Dr. Nevin K. Hiester, of Stanford Research Institute, and Profs. Alan W. Searcy and Leo Brewer, of the University of California. To pinpoint the discussion further, each of the major divisions-methods, materials and processes -was divided into three areas for discussion by separate panels, a panel consisting of a leader and threo others. Thus virtually every aspect of hightemperature research was discussed in thirty-six short papers and in the answers to questions from the floor, in addition to the luncheon address by Dr. Theodore von Kármán, chairman of the Advisory Group for Aeronautical Research and Development, North Atlantic Treaty Organization, whose subject was "Aerodynamic Heating - the Temperature Barrier in Aeronautics".
\end{abstract}

The opening disıussion of several practical methods of obtaining high temperatures by producing images of a heat source covered both optical and mirror furnaces in many different arrangements, employing arcs, flames and the Sun as sources. One of the most novel furnaces was described by Dr. Joseph M. McGreevy, head of the Optics and Nucleonics Branch, Material Laboratory, New York Naval Shipyard. He described a radiant panel consisting of specially developed, long lamps with closely wound tungsten filaments supported in quartz by molybdenum disks. $\mathrm{H} \theta$ reported heating a specimen with such a bank of lamps at a rate of $27 \mathrm{cal} . / \mathrm{sq} . \mathrm{cm}$./sec. with a rather uniform spatial distribution of the heating-rate.

Dr. McGreevy also described another method of heating by direct radiation. In this, oxygen and aluminium rod are fed into the furnace, in which a pool of molten aluminium floats on a lake of aluminium oxide previously? formed during the run. Because of the movement of the aluminium pool, this has been termed the skating-sun furnace. Combustion takes place in the cloud of aluminium vapour just above the pool of aluminium, which provides an irradiance of nearly 20 cal./sq.cm./sec. near the furnace with a temperature of about $3,200^{\circ} \mathrm{K}$.

Dr. Wolfgang Finkelnburg, of the SiemensSchuckertwerke Research Laboratory, described the use of high-intensity electric arcs by which temperatures up to about $53,000^{\circ} \mathrm{K}$. have been obtained.

Dr. Finkelnburg outlined the particle composition of gases at temperatures from about $2,000^{\circ} \mathrm{K}$. to millions of degrees. Of considerable interest was his description of a supersonic plasma jet produced by expanding a water-vapour arc, burning under
50 atmospheres pressure, through a DeLaval nozzle along the axis of the anode.

Of great interest was the discussion by Dr. Heinz Fischer, of the Cambridge (Mass.) Research Center, of electrical discharges of short duration by which temperatures of $250,000^{\circ} \mathrm{K}$. have been achieved. $\mathrm{He}$ also mentioned the work reported in the U.S.S.R. of reactions, employing similar techniques, to touch a million degrees $K$.

As a background for the discussion of materials of interest at elevated temperatures, Dr. John C. Fisher, of the General Electric Co., presented a comprehensive analysis of the various mechanisms for failure in metallic materials exposed to heat. $\mathrm{H}_{\theta}$ presented the idea that high-temperature failure due to cavitation fracture may be controllable by suppression of the intergranular sites at which nucleation of the cavities occurs.

Several speakers pointed out that ceramic materials often show a reasonable amount of ductility at temperatures near their melting points. In particular, Prof. Earl R. Parker, of the University of California, cited several experimental phenomena that indicate the possibility of producing ductile ceramic metals. He showed motion pictures of experiments in which cakes of ice treated with surface-active agents were bent $15^{\circ}$ before failure. A better knowledge of the influence of surface conditions on mechanical behaviour may lesd to the development of ductile ceramic materials.

Progress in development of strong thin ceramic cratings was outlined by $\mathrm{S}$. W. Bradstreet, of the Armour Research Foundation. Among the more interesting new techniques is that of flame spraying, which deposits a cohesive layer of oxide on a metal with little heating of the surface.

Some processes already under investigation require the use of materials near the melting points of the most refractory solids. Prof. J. T. Norton, of the Massa. chusetts Institute of Technology, directed attention to the fundamental chemical factors which result in materials of very high melting points. He demonstrated that high-melting materials can be divided into two distinct classes. The first class is characterized by saturated electronic pair-bonding. It includes such materials as silicon carbide and aluminium nitride. The other class consists of compounds of certæin transition elements with such non-metals as carbon, silicon and boron. Prof. Norton believes the predominant factor in producing this second class of materials is a filling of the $d$ shells of the metal atoms. He suggested that boron phosphide might prove a useful refractory of the first class and that ternary compounds, such as Ta-C-Si compounds, might yield new high-melting materials of the second class.

Because the efficiency of all types of nuclear reactors can be increased by raising the operating temperatures, the importance of the effects of high-energy radiation and fission-product accumulation on hightemperature structural materials is obvious. Because present reactor designs involve rather moderate temperatures, almost no work has been done so far 
on the behaviour of materials at high temperatures in the presence of nuclear fission. There is some information on the effects of radiation on different types of materials at room temperature, however. This information was summarized by Dr. Clifford Weber, of the General Electric Company.

The effects of high pressures on the structure and properties of refractory materials were discussed by both Dean S. S. Kistler, of the University of Utah, and Dr. H. T. Hall, of Brigham Young University. Most startling of their comments was the fact that the melting point of certain refractories has been raised more than 1,000 deg. C. upon application of pressure. On the other hand, with substances that decrease in volume as they melt, the melting point is depressed by pressure. For example, germanium, under pressure, melts at a temperature $600 \mathrm{deg} C$. less than without pressure.

Although the details of the recently publicized successes in the manufacture of diamonds could not be disclosed, Dr. H. T. Hall, who was associated with that work, discussed some of its general aspects. In this he gave a striking example of the power of theoretical examination of high-temperature problems. $\mathrm{H}_{\Theta}$ discussed a calculation demonstrating that known thermodynamic data for graphite and diamond and known kinetic data for conversion of diamond to graphite prove the impossibility of converting graphite to diamond in any temperaturepressure range achievable by conceivable means now possible for the investigation of phenomena that occur at pressures of 200,000 atmospheres and temperatures as high as $500^{\circ} \mathrm{C}$.

Dean Kistler spoke of certain interesting resemblances of boron nitride to graphite. $\mathrm{He}$ directed attention to the fact that, from fundamental considerations, a cubic form of boron nitride with mechanical properties similar to diamond may be expected. The significance of such a possibility is obvious inasmuch as no known material has a hardness between that of boron carbide (2,700 Kroop $\left.\mathrm{K}_{100}\right)$ and diamond $(6,500)$. Dean Kistler held out the hope that a number of completely new materials may be formulated and produced, quite possibly with attractive high-temperature characteristics. As an example he remarked that a new form of silica has been produced simply by compressing quartz above 80,000 atmospheres. Cœsite was also mentioned by Hall as another modification of silica, produced by direct conversion from quartz heated to $2,000^{\circ} \mathrm{C}$. at about 100,000 atmospheres pressure.

Dr. George Duvall and Dr. Milton C. Kells, of Stanford Research Institute, as well as Prof. B. H. Sage, of the California Institute of Technology, mentioned shock waves and high-speed nozzles as useful sources of high-temperature kinetic data. Reactions with half-times as low as five microseconds can be studied in shock tubes. A shock tube can yield a temperature of $11,000^{\circ} \mathrm{K}$. in less than $12 \mu$ sec. High-temperature jets are being actively investigated as commercial sources of gases, such as acetylene.

Progress with the technique of melting and refining metals suspended in space by electromagnetic fields to avoid contamination with container walls was reported by I. E. Campbell, of the Battelle Memorial Institute, and J. C. R. Kelly, of the Westinghouse Electric Corporation. Kelly pointed out that the levitation-melting technique may also be useful for determining the surface tension of molten metals.
The Berkeley meeting made it clear that reactor and jet-engine development will continue to provide a tremendous impetus to research on high-temperature materials, and that high-temperature chemical processing is likely to witness spectacular expansion. It also demonstrated the comparative paucity of information in the high-temperature field. This was underlined by an example given by Kistler. $\mathrm{He}$ pointed out that, although silicon carbide is one of the oldest and best known synthetic high-temperature products, we still do not understand such things as the effects of furnace atmospheres on the rate of its formation, the factors determining whether the cubic or hexagonal form of the compound will be produced, or the effects of impurities on such important properties as conductivity, oxidation resistance, and grinding characteristics. Clearly, much remains to be done.

The papers given by the members of the various panels, with answers to the many questions put from the floor, are being printed and are expected to be issued about October 30; copies will be available from the Public Relations Department, Stanford Research Institute, Menlo Park, California (price 5 dollars each).

\section{CHROMOSOME PROBLEMS}

A

CONFERENCE on chromosomes was held in 1 the Landbouwhogeschool, Wageningen, Holland, during April 16-19, Profs. H. J. C. Tendeloo and R. Prakken being chairman and secretary respectively. The programme consisted of seven lectures with discussions.

Prof. E. Heitz (Tübingen) spoke first on chromosome structure in the nucleus, during mitosis and meiosis.

There are five different types of structural elements recognized in a chromosome: the spiral, the chromomeres, the centromere (primary constriction, kinetochore), the secondary constrictions (SAT-zones) and the heterochromatine. Four of these are directly (heterochromatin) or indirectly (the spiral, the centromere, the SAT-zones) demonstrable in the nucleus. These serve as proof of the individuality of the chromosomes within the nucleus.

The essential element of every chromosome, the spiral, which is tightly coiled during metaphase and anaphase, uncoils during telophase and gives rise, after the calymma has disappeared, to the threadlike structure of the nucleus. This structure has been observed in the living state and can also be demonstrated in the nucleus after fixation.

Often, certain parts of chromosomes do not uncoil during telophase and probably do not lose their calymmatic substance. Since such heterochromatic pieces occupy defined positions within the chromosomes, they can be recognized as more or less compact and highly coloured pieces in their respective positions.

Since rather large pieces of the chromosome on both sides of the centromere are often heterochromatic, the position of the centromere can be demonstrated in the proximal part of the young nucleus.

Chromomeres themselves (that is, compact, small and nucleal positive pieces within the anucleal uncoiled zygotene or pachytene chromosome-fibres seen during meiosis) cannot be demonstrated in the somatic nucleus, although heterochromatic pieces may be mistaken for them. 